Relations industrielles

Industrial Relations

\title{
Comment organiser le classement et les archives, par Giuseppe Continolo, Entreprise Moderne d'Édition, Paris, 1968, 241 pp. Traduit de l'italien par J.-E. Leymarie.
}

\section{Bernard Solasse}

\section{Volume 23, numéro 2, 1968}

URI : https://id.erudit.org/iderudit/027915ar

DOI : https://doi.org/10.7202/027915ar

Aller au sommaire du numéro

Éditeur(s)

Département des relations industrielles de l'Université Laval

ISSN

0034-379X (imprimé)

1703-8138 (numérique)

Découvrir la revue

Citer ce compte rendu

Solasse, B. (1968). Compte rendu de [Comment organiser le classement et les archives, par Giuseppe Continolo, Entreprise Moderne d’Édition, Paris, 1968, 241 pp. Traduit de l'italien par J.-E. Leymarie.] Relations industrielles /

Industrial Relations, 23(2), 375-375. https://doi.org/10.7202/027915ar

Tous droits réservés @ C Département des relations industrielles de l'Université Laval, 1968
Ce document est protégé par la loi sur le droit d'auteur. L'utilisation des services d'Érudit (y compris la reproduction) est assujettie à sa politique d'utilisation que vous pouvez consulter en ligne.

https://apropos.erudit.org/fr/usagers/politique-dutilisation/ 
à partager le système de valeurs des dirigeants. Ce système constitue les prémisses sur lesquelles repose le succès de l'entreprise. Ainsi chaque employé peut obtenir l'assurance qu'il contribue à quelque chose d'utile. On finit par attribuer au chef un certain charisma puisqu'il doit personnaliser, verbaliser et enseigner la religion de l'entreprise. Cependant les délégués syndicaux font figure un peu d'hérétiques en contestant le système de valeur. Pour rendre la négociation plus facile avec ces non-conformistes, Jay propose l'assimilation. La démocratie dans l'entreprise peut se pratiquer en modifiant quelque peu le principe des bicaméralisme: une élite puissante qui élabore les plans et les grandes politiques; un corps populaire et représentatif qui vérifie et critique le réalisme des grandes orientations. Joy illustre ce principe en rappelant le cas du TVA aux Etats-Unis, le cas de Philippe Lamour dans le Languedoc. Sloan, pour ne citer qu'un cos, lorsqu'il prit la direction de GM institua deux comités * The Executive Committee et a The Operations Committee *

Management and Machiavelli n'est pas un livre qui se lit d'un trait. II faut l'aborder chapitre par chapitre. En effet, chaque chapitre est un recueil de réflexions brillantes qui aident à comprendre les problèmes d'équilibre interne et externe que doit solutionner toute organisation gigantesque. Malheureusement, et c'est là le point faible de so démorche, il est impossible après une première lecture de réaliser une intégration intelligente des principes et enseignements qui découlent de chacun des parallèles historiques qu'il a échaffaudés. II reconnait lui-même le manque de rigueur dans la conduite de son analyse. On o un peu, comme lui, l'impression d'être assis en face de quelqu'un qui raconte des histoires de voyageurs. Tout de même chaque histoire contient des enseignements qui sont autant de jalons dans l'édification d'une théorie administrative s'inspirant de lo science et de I'histoire politiques.

\section{Lourent BELANGER}

\section{Comment organiser le classement et les} archives par Giuseppe Continolo, Entreprise Moderne d'Edition, Paris, 1968, 241 pp. Traduit de I'Italien par J.-E. Leymarie.

Ce livre constitue un instrument de trovail précieux pour quiconque est appelé d̀ résoudre des problèmes de classement.

Les trois premières parties traitent: 1) du plan d'archivage et de classement; 2) des méthodes d'archivage; 3) des installations de classement et d'archivage. Ces questions sont abordées dans un vocabulaire simple et selon une progression logique et claire s'appuyant sur des définitions précises. Une bibliographie succinte mais choisie avec pertinence devrait permettre au lecteur de compléter ses connaissances sur l'une ou l'autre question traitée dans cet ouvrage.

La dernière partie du livre par contre qui traite de l'avenir demeure à notre avis très insuffisante. En effet l'introduction du microfilm et des archives automatiques du moins en Amérique du Nord relève non de l'avenir mais est déjà fort répandue. Dans la phase actuelle, l'on assiste au développement du traitement électronique et intégré de l'ensemble de l'information. Cette évolution affecte les entreprises et les administrations les plus importantes, et répond au souci d'accroître l'efficacité et la rationalité du travail administratif.

Bernard SOLASSE

\section{PUBLICATIONS RECENTES}

\section{GÉNÉRALITÉS}

\& Significatif ou non significatif? Réflexions à propos de la théorie et de la pratique des tests statistiques », par G. Calot, Revue de Statistique Appliquée, vol. XV, no 1, 1967, pp. 5-71.

The Economic Approach to Social Questions $\gg$, by Horry $G$. Johnson, Economica, vol. XXXV, no 137, February 1968, pp. 1-22.
\& La politique du progrès technologique \$, par R. Nelson, M.J. Peck et E.D. Kalachek Analyse et Prévision, Tome $V$, no 2, février 1968, pp. $111-123$.

« Les prolongements économiques et sociaux de la recherche scientifique aux Etats-Unis $\gg$, par Pierre Massé, Analyse et Prévision, Tome $V$, no 3, mars 1968, pp. 157-173. 